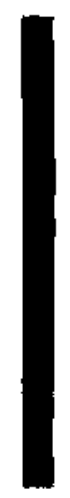

$\mathbf{M}$ alvezzi (1979, p.126), após investigar as atividades dos psicólogos profissionais de recursos humanos na Grande São Paulo, afirma que os psicólogos "não possuem modelos teferenciais de organização que thes forneçam uma visão dos processos organizacionais". Isto porque, entre outras coisas, as próprias escolas de Psicologia nāo demonstram preocupaçāo maior pelos efeitos do seu produto no meio histórico-social. Além disto, lembremonos da organização como realidade complexa que é, uma rede intrincada de variáveis, de difícil apreensảo. Tudo contribui para tornar os psicólogos, em sua maioria, agentes de manutenção do status quo, reprodutores de objetivos técnicos, sem poder de intervenção nos processos decisórios organizacionais.

Fala-se, de alguns anos para cá, em uma crise de identidade do psicólogo, quer atue em pesquisa, em consultório, no magistério, ou em instituições. Isto é particularmente verdadeiro para a Psicologia Organizacional, conforme constata-se em um texto intitulado Psicologia organizacional: qual é o papel desta comissão? do Jornal do CRP-06 (janeiro de 1984, p.4): "A área organizacional é, com certeza, a menos definida em termos de Psicologia. Até há pouco tempo, a atuação do psicólogo nas empresas era vista como essencial apenas e tão somente na seleção de pessoal. Hoje, esta área de atuação está sendo ampliada e, nesta fase de transição, ainda resta muito espaço a ser conquistado, tanto na busca de espaços específicos dos psicólogos, quanto naqueles compartilhados com outras categorias profissionais".

Se considerarmos o objeto de trabalho da atuação em Psicologia Organizacional como as relaçōes entre as condiçōes de ajustamento da organização em seu ambiente, das relaçōes

\title{
Formação e atuação em Psicologia Organizacional*
}

José Carlos Zanelli

Professor do Depto. de Psicologia

da Universidade Brás Cubas, de Mogi das Cruzes,E.S.P.

de interdependência de seus subsistemas e os fatores que determinam tais relações - isto tudo no que concerne especificamente aos recursos humanos - talvez possamos vislumbrar indícios das causas da falta de definiçāo do papel dos psicólogos organizacionais.

Os psicólogos têm atuado, como parece se configurar, no nivel superficial da realidade das organizações e não se preocupam, em profundidade, com o processo organizacional, como algo multideterminado. As noçōes de causalidade e determinação dos eventos sảo precariamente enfatizadas, como se aplicaçōes tópicas ao processo organizacional gerassem, de fato, transformaçōes eficientes e duradouras. Esta falta de clareza, sobre o seu objeto de trabalho, para o próprio profissional, revela implicaçōes contundentes para a sua formação e também para com a forma de perceber a sua atuação.

Voltemos nossos olhos para as escolas (faculdades) de Psicologia. As disciplinas ministradas sob as denominaçôes de Psicologia Industrial, Psicologia Organizacional ou Psicologia do Trabalho, possuem um conteúdo acentuadamente técnico. Salvo exceçōes, ensina-se o como fazer, sem questionar-se o por que fazer. Visam transmitir ao aluno formas de prestaçāo de serviços muito mais dirigidas para indivíduos isolados do que para os processos organizacionais.

Reflitamos sobre alguns aspectos relacionados com a composição dos currículos das escolas de Psicologia. Uma análise dos currículos dos cursos de Psicologia, realizada em 1982 pela Comissāo de Ensino do Conselho Regional de Psicologia $-6^{2}$ Região, re-

"Este artigo faz parte da tese de mestrado apresentada pelo autor ao Instituto Metodista de Ensino Superior de Sāo Bernardo do Campo. velou que existe uma marcada desproporção, nāo favorável à Psicologia Organizacional, entre a quantidade de disciplinas voltadas, direta ou indiretamente, para a preparação dos alunos ao exercício profissional nas organizaçōes e as disciplinas dirigidas para a Psicologia Clínica. Em decorrência, e supondo-se que o modelo clínico tem sido, em geral, calcado ria perspectiva de análise individual de problemas, aos alunos ocorrerá a generalização de tais procedimentos para a empresa. Cabe ainda ressaltar a falta, nos currículos, de disciplinas relacionadas com a Administração e a Economia, como exemplos, que poderiam fornecer subsídios complementares à formação dos alunos, facilitando-lhes a interação com outras categorias que atuam no contexto das organizações, além de facilitar a compreensāo das múltiplas nuanças do processo organizacional. Nas pala. vras de Mello $(1975$, p.60): "os cur. sos ganharam uma unidimensionalidade compacta, de maneira que não apenas formam psicólogos clínicos, mas transformam os alunos, graças ao conteúdo predominante das disciplinas, em psicólogos clínicos" (grifos no original).

Se, do lado da empresa, existe uma indefinição quanto à prescriçāo do papel do psicólogo (Malvezzi, 1979 , p. 117) que é, em contraparti$\mathrm{da}$, igualmente assumida pelo profissional, também é inegável, sem dúvi$\mathrm{da}$, a importância do subsistema comportamental ou psicosocial nas organizações. Trata-se de um subsistema complexo e difuso, e influi em todos os subsistemas, sendo, ao mesmo tempo, causal e instrumental das tarefas organizacionais (Souza, 1975, p. XIV). Novamente recorrendo a Mello $(1975$, p. 51$)$ : "Em resumo, parece. nos que compete aos próprios psicólogos a disputa dos cargos que as empresas, muitas vezes, entregam a elementos com menores qualifica- 
ções, e é nesse sentido que uma formação profissional mais bem cuidada e um interesse por esse tipo de trabatho, criado durante o curso de graduação dos psicólogos, podem favorecer o desenvolvimento da Psicologia Aplicada ao Trabalho".

Face ao exposto até aqui, talvez possa ser resumida a problemática em torno de uma tríade:

1. A indefinição do papel dos psicólogos organizacionais e o caráter técnico de suas contribuições:

2. A falta de prescrição para o papel dos psicólogos por parte da or- ganização e um bloqueio quanto à sua participação nos processos decisórios;

3. A falta, na prática educacional, de um enfoque característico da Psicologia Organizacional que, efetivamente, permita aos alunos uma melhor compreensão dos processos organizacionais, e assim, talvez, lhes facilite apreender as oportunidades de intervenção.

A escola representa, nesta análise, importância crucial, por ser o elemento de potencial detonador rumo às transformaçōes desejadas.
REFERÊNCIAS BIBLIOGRÁFICAS

Comissăo de Ensino do Conselho Regional de Psícología - 6" Regiâo. Análise dos currículos do curso de Psicologia. São Paulo, 1982. Mimeografado.

Comissāo de Psicologia Organizacional do Conselho Regional de Psicologia - $6^{2}$ Regiāo. Psicologia Organizacional: qual é o papel desta comissão? Jornal do CRP06, janeiro de 1984, p. 4.

MALVEZZI, S. O papel dos psicólogos profissionais de recursos bumanos: um estudo na Grande Săo Paula. Pontifícia Universidade Cazólica de São Paulo, 1979. Díssertação de mestrado.

MELLO, Sylvia Leser de. Psicologia $e$ profissão em São Paulo, São Paulo: Atica, 1975.

\section{contraponto}

\section{Jairo E. Borges Andrade}

\section{pesquisador de Recursos Humanos na EMBRAPA}

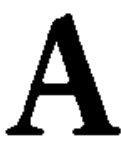

leitura do texto anterior, escrito por José Carlos Zanelli, me estimulou a refletir mais sobre o assunto. Gostaria de colaborar com ele e abrir aqui um espaço para o debate da matéria, discutindo alguns posicionamentos do referido autor e adicionando algumas contribuições ao tema.

Em primeiro lugar, a crise de identidade do psicólogo, especificamente do que atua em organizações, da qual fali-se de alguns anos para cá, tem raízes quee podem ir além daquelas causas citadas por Zanelli, com as quais também concordo. Ela provavelmente advêm dos problemas epistemológicos de que trata Carlos Roberto Drawin (1985) em seu artigo publicado no número anterior da revista Psicologia: Ciência e profissão. Está também relacionada, dessa maneira, à siruacão caótica do campo teórico da Psicologia, à confusão conceitual do seu objeto de estudo e à maneira apressada, pouco cientifica e pouco ética, pela qual experiencias limitadas e isoladas são transformadas em teorias e enfoques. Isso tem levado o profissional à inconunicabilidade com outros e não ao conflito saudável de idéias. Sem definiçōes comuns, sobre as quais possa existir entendimento, e não necessariamente concordância, fica fácil compreender por que há aquela crise de identidade.

Quanto à formação, a dos psicólogos organizacionais muitas vezes se restringe às teorias psicológicas da psicologia social, ignorando a necessária complementação oferecida pela outra metade da área, que sāo as teorias sociológicas da psicologia social. Além disso, a escassez de cursos, especialmente na graduação e freqüentemente na pós-graduação, que enfatizem o conhecimento globalizante na área, cria um provincianismo teórico e prático.

Queremos comentar a citação que Zaneili faz de Mello, a qual afirma que os cursos não apenas formam mas transfor- mam os alunos em psicólogos clínicos. Cremos que, pior que isso, os referidos cursos têm insistentemente mantido nos alunos o ideal de serem profissionais liberais, enquanto a realidade social e de mercado de trabalho de nosso país e até do mundo, apontam para outra direção. Assim, esses cursos deformam todos os tipos de profissionais que precisam trabalhar em equipes, seja como psicólogos organizacionais ou educacionais, ou mesmo aqueles que atuam em instituições hospitalares ou ambulatoriais.

Deve ser ainda lembrada, no contexto da formação, a falta de treinamento sistemático em pesquisa, principalmente em método cientifico, que possibilite ao profissional, não importando seu foco de interesse ou de atuaçāo, desenvolver uma visão crítica dos conhecimentos e técnicas que the forem apresentados no curso $e$, depois, no trabalho. Como bem lembra Silke Weber, 1985, em seu artigo também publicado no número anterior desta Revista, isso näo se adquire somente numa disciplina, mas ao longo de um curso em que determinadas atitudes e habilidades são praticadas por professores e exigidas dos alunos. Perguntamos: é essa a realidade existente na maioria dos cursos de formaçāo de psicólogos?

Gostaríamos, para completar, de discutir o resumo final que Zanelli faz da problemática, em torno de uma tríade. Quanto ao segundo item proposto por ele, cremos que nāo cabe só à organização a falha pela ausência de prescriçāo para o papel do psicólogo. Cabe também a este mudar esta situaçảo, mostrando o que pode (se pode) fazer, além de receber clientes para fazer aconselhamento psicológico dentro da organização (será justo, para com os empregados, serem expostos no seu ambiente de trabalho?), além de realizar treinamentos de relaçöes humanas ou "vivências" como forma de atender suas aspiraçŏes de ser clínico e além de aplicar testes e emitir laudos psicológi- cos. Ademais, é bom ressaltar que o bloqueio quanto à participação nos processos decisórios muitas vezes se cristaliza a partir da incompetência política de muitos profissionais, que se "guardam" e se marginalizam em "setores de psicologia", sob uma visão tecnicista e restritiva imposta por eles próprios.

Finalmente, pedimos licença a Zanelli, para acrescentar mais três pontos àqueles resumidos por ele no artigo anterior. São eles:

- a ausência de uma visão crítica, conceitualmente consistente integradora dos conhecimentos e técnicas da Psicologia, decorrente de uma formação teórica c metodológica segmentada e insuficiente; - a falta de formação (em termos de habilidades e atitudes) e a inexistência de uma visão ética (distinta daquela específica dos profissionais liberais) que possibilitem o trabalho multiprofissional;

- a existência de rejeição quanto a ser agente do patrão ou, como diria Wanderley Codo (1985), a associação do papel do psicólogo organizacional à figura do lobo mau da psicologia. Se o psicólogo possui tal posicionamento ideológico, deve tentar rever o referido papel, ao invés de negá-lo.

\section{REFERENCIAS BIBLIOGRÁFICAS}

\section{CODO, Wanderley. O papel do psicólogo} na organizaçāo industrial (noras sobre o lobo mau em Psicologia). In: Sívia T. M. Lane e Wanderley Codo iorgs.?. Psicologia Social. $O$ homem em movimento. 2. ed. Säo Pauio, teditora Brasiliense, 1985.195-202.

DRAWIN, Carlos R. Ética e Psicologia: por uma demarcaçāo filosófica. Psicologia, Ciência e Profissāa, ano $5, \mathrm{n}^{\circ} 2,1985$, p.14-17.

WEBER, Silke. Currículo mínimo e o espaço da pesquisa na formação do psicólogo. Psicologia, Ciência e Profissão, ano 5, $\mathrm{n}^{\circ} 2,1985$, p.11-13. 